\title{
OS IMPACTOS DA AÇÃO REGULATÓRIA EM DIFERENTES ÁREAS DA SAÚDE PÚBLICA
}

The impacts of regulatory action in different public health areas

${ }^{1}$ Universidade Federal do Rio de Janeiro. Rio de Janeiro/RJ, Brasil.

Correspondência: Verônica Cruz. E-mail: veronicacruzvc@ufrj.br.

Recebido: 31/05/2017. 


\section{Introdução}

O campo de atuação da vigilância sanitária é por natureza amplo e difuso, quase sempre reverberando sobre outras áreas haja vista sua função precípua, qual seja: a de proteger a saúde da população. Não obstante, a atuação da Agência Nacional de Vigilância Sanitária (Anvisa) no Brasil, ao transpassar os limites mais óbvios relativos às questões sanitárias, encontra resistências de ordem política, econômica e até mesmo moral na sociedade. Os artigos que se seguem trazem para a seção “Tema em Debate" desta edição exatamente a diversidade de resistências e conflitos, bem como os interesses antagônicos e desvinculados da proteção à saúde que se colocam cotidianamente aos agentes reguladores desse campo de atuação.

O presente trabalho trata da análise de temas polêmicos, envolvendo atores sociais distintos, porém com grande capacidade de influência na sociedade por meio de ações de propaganda e lobby, políticas públicas, processos judiciais e difusão de valores entre cientistas, pesquisadores e reguladores. Nesse sentido, os três artigos aqui analisados são, de fato, reveladores quanto aos diferentes impactos que a ação regulatória produz na saúde pública em si, mas não apenas nela. Os trabalhos, com muita propriedade, trazem à tona várias evidências de desvios presentes nas interações sociais envolvendo agentes do mercado, políticos, membros do Poder Judiciário, profissionais de saúde, cientistas, pesquisadores e reguladores. Os fatos e discussões providos por esses estudos dão conta da variedade de desafios colocados hoje à Anvisa, e também a um conjunto de instituições públicas no Brasil.

\section{Bioética, o cuidado com o outro na vigilância sanitária}

Os especialistas Garrafa, Amorim, Garcia e Manchola nos atualizam quanto ao conceito de bioética - que classificam como novo, tendo em vista seu quase meio século de existência, mas que hoje, sem dúvida, mostra-se fundamental. Quando a história, por meio dos registos do pós-guerra, nos obriga a reconhecer o quanto fez falta à humanidade um conjunto de crenças e valores balizadores das escolhas científicas e tecnológicas é que fica ainda mais evidente a relevância da incorporação desse conceito nas práticas regulatórias do campo sanitário. Além das experiências cometidas pelos nazistas, os autores destacam outros episódios recentes passíveis de cuidado e investigação quanto suas consequências para as pessoas, como o uso da energia nuclear, a utilização terapêutica de células tronco-embrionárias, a novas formas de reprodução, os produtos transgênicos e as agressões ao meio ambiente. Embora possam parecer temas distantes de um indivíduo comum, tais questões estão mais próximas do que se pode imaginar, e a velocidade com que algumas dessas experiências são incorporadas a cotidiano induz à reflexão sobre o que se conhece de fato sobre seus efeitos adversos.

Os autores descrevem como esse conceito foi se consolidando à luz de variadas influências filosóficas, e ainda como sua evolução ao longo do tempo permitiu que o conceito de bioética amadurecesse a ponto de incluir novos parâmetros e 
direcionamentos para além da ciência e da tecnologia. A bioética amplia a agenda de trabalho e passa a incorporar também temas relativos aos campos sanitário, social e ambiental. Conforme explicam os autores, tais avanços não surgiram espontaneamente, mas devido à pressão de países e organismos internacionais, que criticavam a estreita perspectiva adotada anteriormente. A partir da regulação internacional, via organismos como a Unesco, impõe-se a base ética para o desenvolvimento científico e tecnológico. Esse debate se desenvolve e sofre influências regionais e culturais, tendo em vista as distintas realidades político-sociais sobre as quais ele se aplica.

Ao associar bioética e regulação, os autores chamam atenção para o fato de o entendimento do que venha a ser regulação sanitária segundo a Declaração Universal de Bioética e Direitos Humanos (DUBDH), produto de amplo debate, e o entendimento da Anvisa serem convergentes. Ambos se harmonizam quanto à compreensão de que é dever do Estado, por meio de seus poderes legislativo e normativo, monitorar e afastar a população de possíveis efeitos adversos provenientes de exposições natural ou artificialmente criadas. Dito de outra forma, os autores desse trabalho enfatizam, como elemento essencial da atividade regulatória, o cuidado com as pessoas e também com o meio ambiente, sem, no entanto, fixar obstáculos para o avanço da ciência e da tecnologia. Ao adicionarem a perspectiva da bioética de intervenção (BI), ancorada nos princípios de prudência, precaução, proteção e prevenção, os autores concluem que, para os reguladores que atuam no campo da vigilância sanitária, a bioética não só é uma valiosa orientação teórica, como, sobretudo, uma fundamental e indispensável ferramenta de trabalho.

\section{A Anvisa e sua interação com outros entes públicos}

Com um olhar empírico sobre a realidade regulatória brasileira ao analisar os casos dos inibidores de apetite e da fosfoetalonamina sintética, o trabalho de Faleiros e Andrade argumenta que a fragilização da Anvisa observada nos dois casos se deve ao que os autores denominam como "interferência" do Congresso Nacional, ao qual não caberia "usurpar" a análise "essencialmente" técnica da agência reguladora. A despeito de discordar dessa afirmação, sobretudo nos termos em que os autores colocam, pode-se classificar esse trabalho como uma poderosa análise das relações entre o Poder Executivo com os demais poderes, cujas dinâmicas e pontos de equilíbrio se tangenciam e se repelem, a depender dos interesses envolvidos. Mais especificamente, esse estudo aponta os desafios de interação da Anvisa com outros órgãos do Poder Executivo e com os poderes Legislativo e Judiciário.

Nesse artigo, fica evidente o modo como decisões da Anvisa, na forma de resoluções de diretoria colegiada (RDC), foram revisadas no âmbito do Poder Legislativo e do Poder Judiciário, tanto sobre os inibidores de apetite quanto sobre a fosfoetalonamina sintética (conhecida como a "pílula do câncer"). Em ambos os casos, a base técnica foi ora questionada ora considerada. Tal fato demostra que a 
visão técnico-científica sobre questões sanitárias não predomina, como poderia supor a Bioética, objeto do artigo anterior. A depender de cada instituição, seus agentes podem ser mais ou menos afeitos ao cuidado com a saúde da população. Especialmente no caso do Poder Legislativo, instituição mais "sensível" à opinião pública por depender do voto direto, observa-se a preocupação em atender demandas imediatas sem o devido respaldo técnico.

Ao descrever rapidamente a evolução da tomada de decisões sobre os dois temas analisados, o trabalho revela a força e as estratégias de poderosos agentes do mercado e de setores da saúde que buscam constantemente alterar ou escapar das arenas decisórias que não lhes favorecem. A partir desse estudo, fica claro como os agentes regulados ou indiretamente afetados por decisões burocráticas buscam meios alternativos de escapar dessas arenas regulatórias. Uma das estratégias é deslocar o debate para outra instituição que, ainda que também seja uma arena regulatória marcada por conflitos, mostra-se mais "sensível" e favorável aos interesses do mercado. Este é novamente o caso do Parlamento brasileiro. Outra opção é sempre a judicialização, na qual o debate pode ser estendido enquanto decisões desfavoráveis forem suspensas longa ou terminantemente.

\section{Ineficácia regulatória e incapacidade de fiscalização?}

O artigo de Castilho e Abdala demostra como a legislação sanitária é francamente descumprida no Brasil, a partir de uma análise da propaganda de medicamentos destinada aos profissionais de saúde. De acordo com a pesquisa, a rigor nenhuma das peças publicitárias analisadas no estudo cumpria integralmente as determinações da legislação. As autoras afirmam que o descumprimento se apoia na impunidade das indústrias de medicamentos e de propaganda, que, negligenciando os impactos nocivos dessa ação sobre a população, seguem fazendo investimentos vultosos em publicidade.

O artigo apresenta, por meio da análise de uma amostra não aleatória de peças publicitárias, irregularidades de toda ordem: informações obrigatórias ausentes, ilegíveis ou incompletas; propagandas disponíveis ilegalmente na internet; entre outros problemas. As autoras destacam a fragilidade das punições impostas pela Anvisa por meio de multas, o que não a exime de estabelecer outros meios para controlar a forma como os medicamentos são apresentados à população, mesmo que se destinem a um público-alvo específico.

\section{Considerações finais}

A perspectiva de que os princípios e valores que constituem a bioética não deveriam recair apenas sobre o desenvolvimento científico e tecnológico, mas sim em todas as ações, intervenções e políticas públicas que reverberam sobre pessoas e meio ambiente, torna-se gritante quando relacionada aos estudos aqui apresentados. 
Segundo a análise do processo decisório de substâncias cujos efeitos são pouco conhecidos ou adversos, o padrão de interação das instituições que compõem os três poderes revelou-se até mesmo irresponsável, na medida em que expôs a população ao risco. Sobre este ponto, é válido destacar a atuação dos parlamentares, cujas campanhas eleitorais, muitas vezes financiadas por agentes dos setores regulados, faz com que se voltem para o favorecimento do mercado em detrimento do interesse público.

Por sua vez, a análise da publicidade de medicamentos traz evidências de uma agência reguladora que elabora normas, mas não é capaz de verificar seu cumprimento ou imprimir punições duras aos setores regulados. De acordo com essa análise, o problema reside na incapacidade fiscalizatória de uma agência que não dispõe dos mecanismos requeridos para se estruturar e se contrapor à poderosa indústria farmacêutica. Enquanto perdurar esse quadro, a agência reguladora permanecerá incapaz de induzir comportamentos desejados por parte dos setores regulados.

A análise dos artigos selecionados nos faz reafirmar a necessidade da regulação no campo da vigilância sanitária e da confiança nela, posto não ser possível prescindir de seu papel cuidador da saúde da população. Porém, os trabalhos analisados chamam atenção para o fato de que esse sentido da atividade regulatória ainda não é difuso nem mesmo entre os representantes da sociedade. Primeiramente, a regulação, tida como cuidado da pessoa humana e do meio ambiente, precisa ocupar o campo dos valores e se fazer difundir entre representantes, magistrados, setores regulados e mesmo entre os reguladores. A bioética insere-se, nesse sentido, como o suporte ideal para o desempenho responsável da atividade regulatória, baseada no cuidado com o outro e comprometida com a saúde da população e do meio ambiente.

Finalmente, cabe afirmar que, embora os estudos que compõem esta seção revelem inúmeras fragilidades de órgãos, agentes e decisões da administração pública e dos agentes da sociedade que com ela se relacionam, a tomada de decisão em um ambiente democrático é um processo aberto. Assim, cabe aos envolvidos e interessados no tema da regulação sanitária entender que é possível apreender e aperfeiçoar esse processo decisório, tornando-o mais inclusivo, justo e voltado para o bem-estar dos indivíduos.

Verônica Cruz - Doutora em Ciência Política. Professora Adjunta da Universidade Federal do Rio de Janeiro. Rio de Janeiro/RJ, Brasil.E-mail: veronicacruzvc@ufrj.br. 